Check for updates

Cite this: RSC Adv., 2019, 9, 23261

\title{
Role of polysilicon in poly-Si/SiO $x$ passivating contacts for high-efficiency silicon solar cells
}

\begin{abstract}
HyunJung Park, (D) *a Soohyun Bae, ${ }^{a}$ Se Jin Park, ${ }^{a}$ Ji Yeon Hyun, ${ }^{a}$ Chang Hyun Lee, ${ }^{a}$ Dongjin Choi, ${ }^{a}$ Dongkyun Kang, ${ }^{a}$ Hyebin Han, ${ }^{a}$ Yoonmook Kang, $\dagger^{\mathrm{b}}$ Hae-Seok Lee $\dagger^{\mathrm{b}}$ and Donghwan Kim ${ }^{\mathrm{ab}}$

In this study, we focused on understanding the roles of a polysilicon (poly-Si) layer in poly-Si/SiO ${ }_{x} / \mathrm{c}-\mathrm{Si}$ passivating contacts. Passivating contact formation conditions were varied by changing the doping method, annealing temperature and time, polysilicon layer thickness, and polysilicon doping concentration. Our observations indicated that the roles of polysilicon are contact, in-diffusion barrier action, field effect, gettering, and light absorption. Based on the observations, a i $V_{\mathrm{OC}}$ of $741 \mathrm{mV}$ was obtained. Finally, to increase $J_{\mathrm{SC}}$ with high $V_{\mathrm{OC}}$, the polysilicon was etched after hydrogenation to reduce light absorption with high passivation quality. i $V_{O C}$ was not affected by etching; moreover, by etching the polysilicon from $300 \mathrm{~nm}$ to $60 \mathrm{~nm}$, the cell efficiency increased from $20.48 \%$ to $20.59 \%$ with increasing $J_{\mathrm{SC}}$, constant $V_{\mathrm{OC}}$, and fill factor.
\end{abstract}

Received 12th May 2019

Accepted 22nd July 2019

DOI: $10.1039 / \mathrm{c} 9 \mathrm{ra03560e}$

rsc.li/rsc-advances heterojunction or HIT. ${ }^{15-18}$ The $\mathrm{SiO}_{x}$-based passivating contacts consist of $\mathrm{SiO}_{x}$ and polycrystalline silicon (poly-Si) in a stack structure, and the cells using poly-Si/SiO ${ }_{x}$ passivating contacts are referred to as tunnel oxide passivated contact (TOPCon), ${ }^{8,19-22}$ semi-insulating polycrystalline silicon (SIPOS), ${ }^{23,24}$ polycrystalline silicon on oxide (POLO), ${ }^{25,26}$ or poly-Si passivating contact. ${ }^{27-30}$ Additionally, it should be noted that EPFL recently published a study on $\mathrm{SiO}_{x}$-based passivating contact using silicon-rich silicon carbide instead of poly-Si. ${ }^{31}$ In HIT cells, the highest recorded efficiency for an interdigitated back contact (IBC) structure was $26.7 \%$ (ref. 16 and 17) and that for a front and rear contact structure was $24.7 \% .^{18}$ However, heterojunction solar cells have process temperature limits. ${ }^{32-36}$ Therefore, another passivating contact structure with $\mathrm{SiO}_{x} /$ poly$\mathrm{Si}$, instead of amorphous silicon, has attracted the interest of researchers. In poly-Si passivating contact cells, the highest efficiency of $26.1 \%$ and $25.8 \%$ for $\mathrm{IBC}^{25}$ and front and rear contact structures ${ }^{17,37}$ were reported, respectively. This efficiency is remarkable because it is the highest efficiency using the front and rear contact.

With respect to poly-Si passivating contact, many researchers have focused on understanding the characteristics of silicon oxide. ${ }^{9,38-41}$ In this research, we attempted to focus on poly-Si to understand the relationship between poly-Si and the properties of passivating contact solar cells including electrical and passivation properties. Thus, in this study, we varied the doping method, annealing temperature and time, poly-Si thickness, and doping concentration. For the characterization, we measured the implied open circuit voltage (i $\left.V_{\mathrm{OC}}\right)$, doping concentration profile, and the thickness and crystallinity of poly-Si using quasi-steady-state photoconductance (QSSPC), ${ }^{\mathbf{4}}$
${ }^{a}$ Department of Materials Science and Engineering, Korea University, Seoul 02841, Republic of Korea. E-mail: jung1029@korea.ac.kr; Tel: +02 32903713

${ }^{b}$ KU-KIST Green School Graduate School of Energy and Environment, Korea University, Seoul 02841, Republic of Korea

$\dagger$ These authors contributed equally to this work. 
secondary ion mass spectroscopy (SIMS), transmission electron microscopy (TEM), and atom probe tomography (ATP), respectively.

\section{Experimental procedure}

N-type crystalline silicon wafers grown using the Czochralski method were used. The thickness and resistivity of the wafer were $180 \mu \mathrm{m}$ and $4.5 \Omega \mathrm{cm}$, respectively. After saw-damage etching using $\mathrm{KOH}$, a silicon oxide layer with a thickness of $1.2 \mathrm{~nm}$ was grown on the wafer surface via wet chemical oxidation using $\mathrm{H}_{2} \mathrm{O}_{2}{ }^{43}$ Subsequently, two types of poly-Si layers: intrinsic poly-Si and in situ P-doped poly-Si, were deposited on the silicon oxide surface using low pressure chemical vapor deposition (LPCVD) equipment at $600{ }^{\circ} \mathrm{C}$. The thickness of the intrinsic poly-Si was varied from 50 to $300 \mathrm{~nm}$ and $\mathrm{POCl}_{3}$ diffusion was conducted to dope the intrinsic poly-Si. In the pre-deposition step, a $\mathrm{POCl}_{3}: \mathrm{O}_{2}$ gas mixture with varied ratio from $200: 800$ to $800: 200$ was used to control the poly-Si doping concentration. The deposition temperature and time were fixed at $740{ }^{\circ} \mathrm{C}$ and $20 \mathrm{~min}$, respectively. After predeposition, the samples were annealed at temperatures between 800 and $950{ }^{\circ} \mathrm{C}$ from 10 to $60 \mathrm{~min}$ in a $\mathrm{N}_{2}$ atmosphere. For in situ P-doped poly-Si, the samples were annealed in the same furnace that was used to anneal $\mathrm{POCl}_{3}$-diffused poly-Si in the $\mathrm{N}_{2}$ atmosphere after the deposition of the in situ P-doped poly-Si. The annealing temperature and time were changed from 800 to $950{ }^{\circ} \mathrm{C}$ and 10 to $60 \mathrm{~min}$, respectively. After annealing, both $\mathrm{POCl}_{3}$-diffused poly-Si and in situ P-doped polySi were dipped in diluted HF acid to etch PSG and native $\mathrm{SiO}_{x}$ on poly-Si. Subsequently, the samples were subjected to hydrogenation to further improve the passivation quality by depositing the stacked layers of $\operatorname{SiN}_{x}$ and $\mathrm{Al}_{2} \mathrm{O}_{3}$ with subsequent annealing at $600{ }^{\circ} \mathrm{C}$ for $15 \mathrm{~min}$ in a $\mathrm{N}_{2}$ atmosphere. Plasma-enhanced chemical vapor deposition (PECVD) and atomic layer deposition (ALD) were used to deposit $\mathrm{SiN}_{x}$ and $\mathrm{Al}_{2} \mathrm{O}_{3}$, and rapid thermal process (RTP) was used to anneal them. The stacked layers of $\mathrm{SiN}_{x}$ and $\mathrm{Al}_{2} \mathrm{O}_{3}$ were removed by dipping in diluted $\mathrm{HF}$. For subsequent experiments on etching poly-Si, an acidic mixture composed of $\mathrm{HNO}_{3}: \mathrm{H}_{2} \mathrm{O}: \mathrm{HF}=300: 100: 10$ by volume was used. The passivation quality of the poly-Si contact was analyzed by $\mathrm{i} V_{\mathrm{OC}}$, measured using the QSSPC. The doping concentration profile was measured using SIMS measurement. TEM measurement was used to confirm the thickness and crystallinity of the poly-Si. Moreover, after preparing the abovementioned sandwich-structured samples to measure the QSSPC, we fabricated the passivating contact solar cell. The schematics of detailed sample structure and cell structure are presented in Fig. 1.

\section{Results}

\subsection{Controlling passivation quality}

3.1.1 Comparison of doping methods and poly-Si thickness. First, we compared two doping methods to form $\mathrm{n}+$ poly$\mathrm{Si}$, namely, ex situ doping by depositing intrinsic poly-Si through LPCVD and phosphorus doping through $\mathrm{POCl}_{3}$ (a) $\mathrm{POCl}_{3}$ diffused poly-Si contact

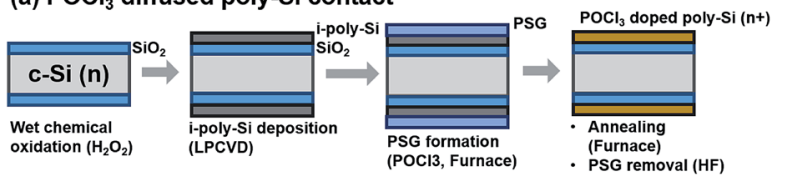

(b) in-situ P doped poly-Si contact

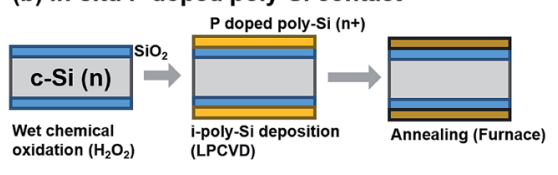

(c) Etching of poly-Si
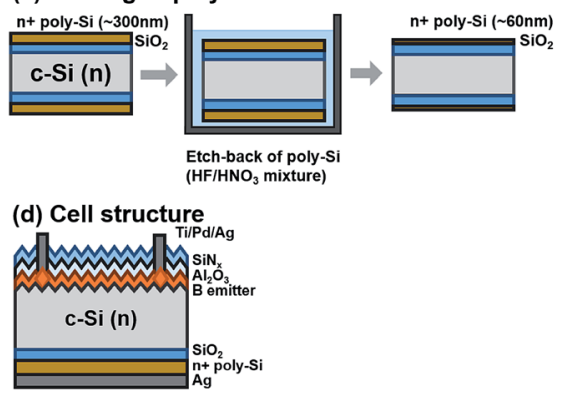

Fig. 1 Schematic of sample structure for (a) $\mathrm{POCl}_{3}$-diffused poly-Si contact, (b) in situ P-doped poly-Si contact, (c) etched poly-Si contact, and (d) the final cell structure.

diffusion, and in situ doping by directly depositing the phosphorus doped poly-Si using LPCVD. As the annealing temperature and time increased, the passivation quality of the poly-Si contacts changed, as shown in Fig. 2(a). Increasing the annealing temperature improved the passivation quality, and increasing the annealing time led to the commencement of deterioration of $\mathrm{i} V_{\mathrm{OC}}$ for both $\mathrm{ex}$ situ- and in situ-doped poly-Si contacts. Moreover, $\mathrm{i} V_{\mathrm{OC}}$ of the in situ $\mathrm{P}$ poly-Si was higher than that of the $\mathrm{POCl}_{3}$-diffused poly-Si, and the decrease in the rate of $\mathrm{i} V_{\mathrm{OC}}$ of in situ $\mathrm{P}$ poly-Si was lower than that of $\mathrm{POCl}_{3}$ diffused poly-Si.

Thus, a different $\mathrm{i} V_{\mathrm{OC}}$ behavior between in situ $\mathrm{P}$ poly-Si and $\mathrm{POCl}_{3}$-diffused poly-Si in the degradation rate of $\mathrm{i} V_{\mathrm{OC}}$ could be due to the PSG layer. The doping concentration of PSG layer is approximately $1 \times 10^{21} \mathrm{~cm}^{-3}$, which generates three times higher flux because the doping concentration difference between $\mathrm{POCl}_{3}$-diffused poly-Si and in situ $\mathrm{P}$ doped poly-Si is three times greater. Owing to this high flux, the dopant atoms diffuse from PSG to poly-Si. This accelerates the deterioration of $\mathrm{i} V_{\mathrm{OC}}$ as the diffusion of $\mathrm{P}$ from poly-Si to c-Si increases, as shown in Fig. 2(d). Consequently, an important role of poly-Si is that of an in-diffusion barrier. It should be noted that the in situ doping method is more suitable owing to a lower extent of in-diffusion.

Additionally, we grew a PSG layer on in situ poly-Si to investigate the effect of a PSG formation step on the characteristics of the poly-Si contact. After growing the PSG layer, it was removed and annealed at $950{ }^{\circ} \mathrm{C}$ for $20 \mathrm{~min}$ in $\mathrm{N}_{2}$. Consequently, the addition of the PSG growth step decreased the $\mathrm{i} V_{\mathrm{OC}}$ by $15 \mathrm{mV}$. This result indicates that the PSG growth step affects passivation quality. A further in-depth study will be required to understand the cause of $i V_{\mathrm{OC}}$ due to the addition of the PSG 
(a)

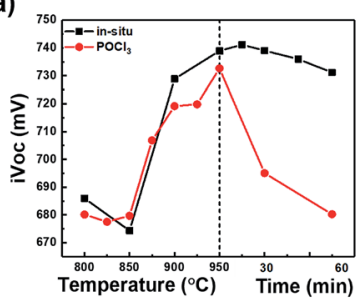

(c)

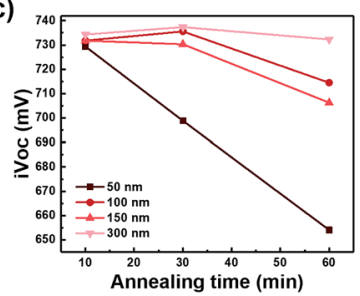

(e)

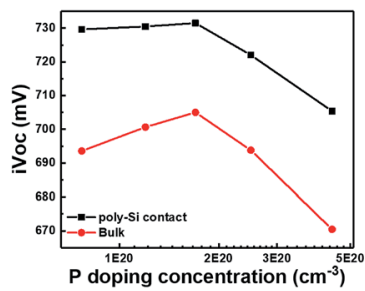

(b)

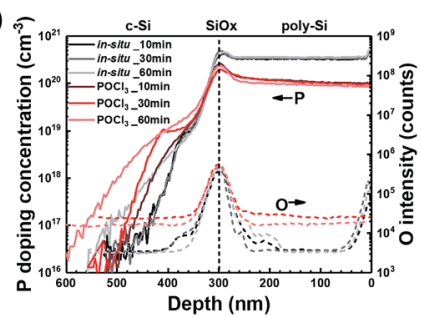

(d)

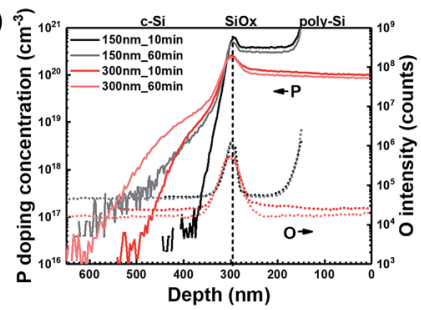

(f)

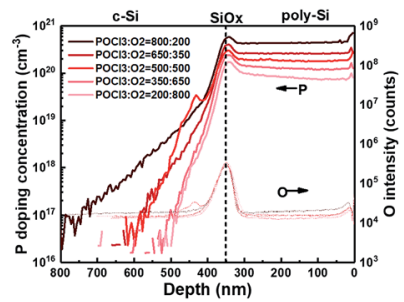

Fig. 2 i $V_{\mathrm{OC}}$ of poly-Si passivating contacts as a function of (a) annealing temperature, time required for different doping methods, and (c) annealing time for different thicknesses. (e) $P$ doping concentration at poly-Si. (b, d, f) P doping concentration profile (solid line) and oxygen intensity profile (dotted line) of (a, c, e), respectively

formation step as well as the effect of the PSG growth step on the tunnel oxide or poly-Si layer.

3.1.2 Comparison of thicknesses of poly-Si. Second, we changed the thickness of poly-Si from 50 to $300 \mathrm{~nm}$ by depositing different thicknesses of intrinsic poly-Si with subsequent doping process using $\mathrm{POCl}_{3}$ diffusion with annealing at $950{ }^{\circ} \mathrm{C}$ for $10 \mathrm{~min}$. From the first experimental result, a change in the thickness of poly-Si was expected to affect the rate of decrease in $\mathrm{i} V_{\mathrm{OC}}$ because the in-diffusion would be higher for a thinner poly-Si. To verify this, we deposited intrinsic poly-Si with different thicknesses varying from 50 to $300 \mathrm{~nm}$. The decrease in $\mathrm{i} V_{\mathrm{OC}}$ was accelerated with the decreasing thickness of poly-Si. This indicates that poly-Si should act as an in-diffusion barrier and should be sufficiently thick to prevent in-diffusion according to the annealing temperature and time.

3.1.3 Comparison of doping concentrations. Third, the doping concentration at poly-Si was controlled by varying the mixture ratio of the source gas in the pre-deposition step. Thus, the poly-Si doping concentration was changed from $8 \times 10^{19}$ $\mathrm{cm}^{-3}$ to $4.5 \times 10^{20} \mathrm{~cm}^{-3}$ as the $\mathrm{POCl}_{3}: \mathrm{O}_{2}$ gas flow rate ratio was changed from $200: 800$ to $800: 200$, as shown in Fig. 2(f). The passivation quality increased when the doping concentration was increased from $8 \times 10^{19} \mathrm{~cm}^{-3}$ to $1.8 \times 10^{20} \mathrm{~cm}^{-3}$ but started to decrease rapidly with a further increase in the doping concentration from $1.8 \times 10^{20} \mathrm{~cm}^{-3}$ to $4.5 \times 10^{20} \mathrm{~cm}^{-3}$. This implies that a decrease in $\mathrm{i} V_{\mathrm{OC}}$ with an increase in doping concentration will be caused by in-diffusion because in-

diffusion increases as the doping concentration increases, as shown Fig. 2(f). Additionally, the decrease in $\mathrm{i} V_{\text {OC }}$ could be due to the precipitates or clusters from the inactive $\mathrm{P}$ because the doping concentration at poly-Si is higher than the solubility limit, which is $4 \times 10^{20} \mathrm{~cm}^{-3}$ at $950{ }^{\circ} \mathrm{C}^{44}$ The reason for the increase in $\mathrm{i} V_{\text {OC }}$ with an increase in doping concentration is not clearly understood in our study. However, we suggest some possibilities that a high doping concentration would increase the field effect or gettering.

(1) Field effect by doping concentration at poly-Si. According to the TSU-ESAKI tunneling current model, ${ }^{45}$ the tunneling current is a function of the transmission coefficient (TC), which is determined by calculating the barrier height between c-Si/ $\mathrm{SiO}_{x}$ and the supply function. These, in turn, are determined using the difference in carrier concentration at the interfaces of the $\mathrm{SiO}_{x}$ layer. As the doping concentration at poly-Si changes from $8 \times 10^{19} \mathrm{~cm}^{-3}$ to $2 \times 10^{20} \mathrm{~cm}^{-3}$, the value of $\Delta E_{\mathrm{C}}$ changes from 0.291 to $0.311 \mathrm{eV}$. This results in an increase in the electron tunneling current. Therefore, we concluded that the tunneling current changes when the doping concentration at poly-Si changes.

(2) Gettering effect by doping concentration at poly-Si. The gettering effect of the poly-Si passivating contact was studied by A. Liu. ${ }^{10,11}$ In our research, the gettering effect was confirmed by etching poly-Si/SiO ${ }_{x}$ and the in-diffused region, and repassivating the sample using a $10 \mathrm{~nm}$-thick aluminum oxide layer. We confirmed that by increasing the doping concentration from $8 \times 10^{19} \mathrm{~cm}^{-3}$ to $1.8 \times 10^{20} \mathrm{~cm}^{-3}$, the bulk quality improved as $\mathrm{i} V_{\mathrm{OC}}$ after etching the poly-Si/c-Si, from 693 to $705 \mathrm{mV}$. This implies that a slight increase also caused the gettering effect, with an improvement in the bulk quality. However, further increase in doping concentration caused the drop in bulk $\mathrm{i} V_{\text {OC }}$ from 710 to $670 \mathrm{mV}$. This might be caused by the reappearance of gettered impurities, which is also represented by Liu et al. ${ }^{11}$

Thus, we concluded that poly-Si is required for contact because $\mathrm{SiO}_{x}$ would get destroyed without poly-Si. The poly-Si layer plays the following roles: (1) contact, (2) in-diffusion barrier, and provides (3) field effect and (4) gettering. A highquality passivating contact can be realized using thick poly-Si to reduce in-diffusion and a high doping concentration is used to enhance the passivation quality and gettering effect.

\subsection{Effect of hydrogenation}

The effect of hydrogenation was investigated by comparing $\mathrm{i} V_{\mathrm{OC}}$ before and after hydrogenation. In Fig. 3(a-c), delta i $V_{\mathrm{OC}}$ represents $\mathrm{i} V_{\mathrm{OC}}$ after hydrogenation on subtracting $\mathrm{i} V_{\mathrm{OC}}$ before hydrogenation. Delta $\mathrm{i} V_{\mathrm{OC}}$ was higher for a lower annealing temperature, shorter time, greater thickness, and lower doping concentration. This implies the following: (1) if the annealing condition is suitable for poly-Si contact with high $\mathrm{i} V_{\text {OC }}$, the effect of hydrogenation decreases, and (2) if phosphorus indiffusion critically affects $\mathrm{i} V_{\text {OC }}$, the effect of hydrogenation decreases. Thus, we conclude that in-diffusion is a critical factor that must be avoided for high passivation quality. Moreover, if in-diffusion does not have a critical effect, the annealing 
(a)

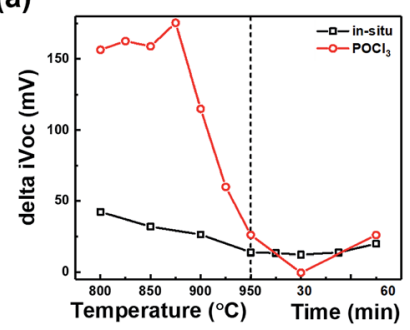

(b)

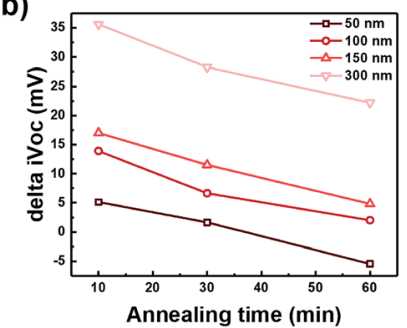

(c)

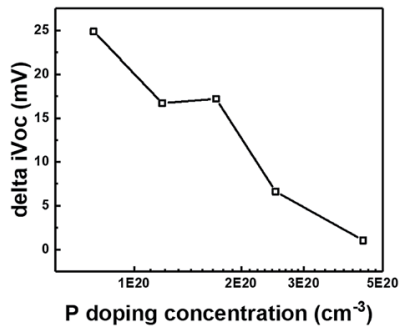

Fig. 3 Delta $\mathrm{iV}_{\mathrm{OC}}$ of poly-Si passivating contacts after and before hydrogenation as a function of (a) annealing temperature, time for different doping methods, and (b) annealing time for different thicknesses, and (c) $\mathrm{P}$ doping concentration at poly-Si.

condition should be controlled to maximize the passivation quality.

In Fig. 4, 2D and 3D hydrogen concentration profiles of hydrogen atoms were measured using SIMS and ATP, respectively. Fig. 4(a) demonstrates an increase in the concentration of hydrogen atoms at the $\mathrm{SiO}_{x}$ layer after hydrogenation. For the 3D profile analysis shown in Fig. 4(b-d), the peak of hydrogen concentration corresponds to that of oxygen concentration. Additionally, a slightly higher hydrogen concentration was confirmed at the surface of poly-Si/SiO ${ }_{x}$ in the 3D mapping as compared to the surface of $\mathrm{SiO}_{x} / \mathrm{c}$-Si. In conclusion, the result shows that the position of hydrogen atoms is correlated to the position of oxide layer.

3.2.1 $\mathrm{i} V_{\mathrm{OC}}$ after etching of poly-Si. As poly-Si plays the role of (1) contact, (2) in-diffusion barrier, and provides a (3) field effect and (4) gettering, a thicker poly-Si with higher doping concentration is preferred. However, the thicker poly-Si leads to higher current loss because it has a higher infrared carrier absorption, which reduces light trapping and decreases the short-circuit current density $\left(J_{\mathrm{SC}}\right)$. Therefore, poly-Si should be thin to decrease the light absorption at poly-Si, which affects $J_{\mathrm{SC}}$. Therefore, in this section, we etched poly-Si after hydrogenation and measured $\mathrm{i} V_{\mathrm{OC}}$. The result, which is shown in Fig. 5(a), indicates that the passivation quality is not affected owing to

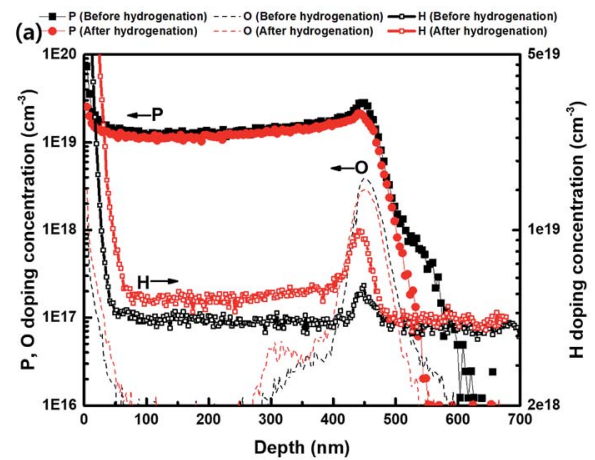

(b)

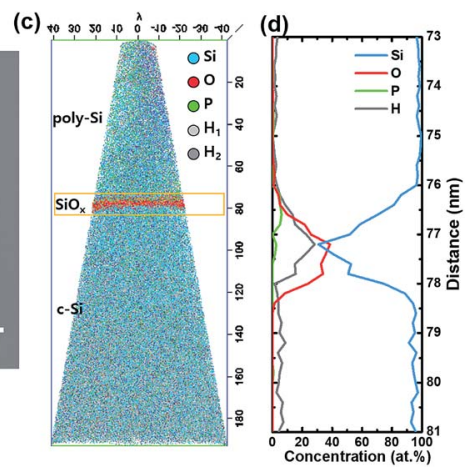

Fig. 4 (a) Doping concentration profiles of phosphorus, oxygen, and hydrogen as a function of the depth of the poly-Si passivating contact. Profiles are compared before and after hydrogenation. (b) TEM image of the poly-Si passivating contact and atom probe tomography (APT) measurement result, which shows (c) three-dimensional map of the atoms, (d) one-dimensional doping concentration graph of the interface.

the etching of poly-Si. However, with further etching of poly-Si, $\mathrm{i} V_{\mathrm{OC}}$ starts to decrease owing to the destruction of $\mathrm{SiO}_{x}$. To elucidate this, TEM analysis of the poly-Si contact was performed. The TEM images, which are shown in Fig. 5(b-i), confirm that poly-Si is etched and the $\mathrm{SiO}_{x}$ layer is not affected. After etching $300 \mathrm{~nm}$, the poly-Si was almost fully etched and the $\mathrm{SiO}_{x}$ layer remained, as shown in Fig. 5 (e and i). This implies that (1) $\mathrm{SiO}_{x}$ is the most important passivation layer because $\mathrm{i} V_{\mathrm{OC}}$ was not affected by almost completely etching the poly-Si layer, and (2) the poly-Si layer is required to protect the $\mathrm{SiO}_{x}$ layer from high-temperature annealing and hydrogenation process to enhance the passivation quality of the $\mathrm{SiO}_{x}$ layer. Therefore, the roles of poly-Si are now (1) as a contact, (2) as an in-diffusion barrier, (3) to provide the field effect and tunneling, (4) to provide gettering, and (5) as a light absorption layer, which can be etched to possess high $V_{\mathrm{OC}}$ and $J_{\mathrm{SC}}$. The poly-Si layer is also required as a protective layer for the $\mathrm{SiO}_{x}$ layer to prevent the destruction of the $\mathrm{SiO}_{x}$ layer during process steps such as annealing, metallization, and hydrogenation.

3.2.2 Improvement in solar cell efficiency of passivating contact by etching of poly-Si. Finally, we fabricated a passivating contact silicon solar cell by etching poly-Si from 300 to $50 \mathrm{~nm}$ to enhance $J_{\mathrm{SC}}$. First, the EQE data and reflectance graph showed that the etching of poly-Si increased the rear reflection, which thereby increased the EQE at the short and long wavelengths, as 
(a)

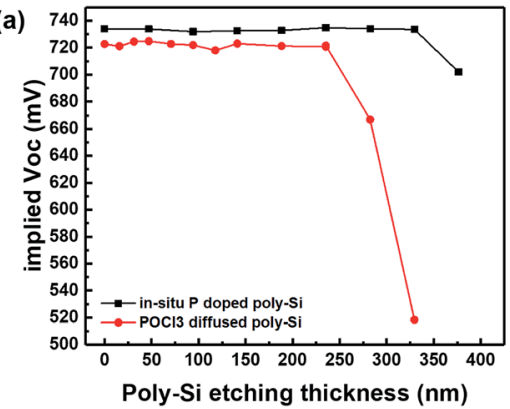

(b)

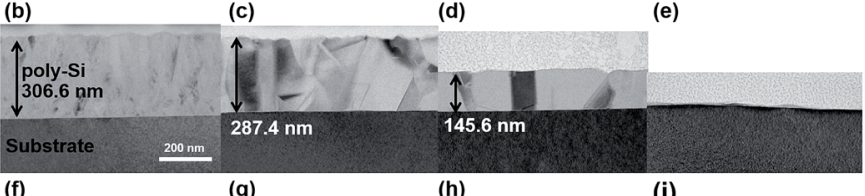

(f)

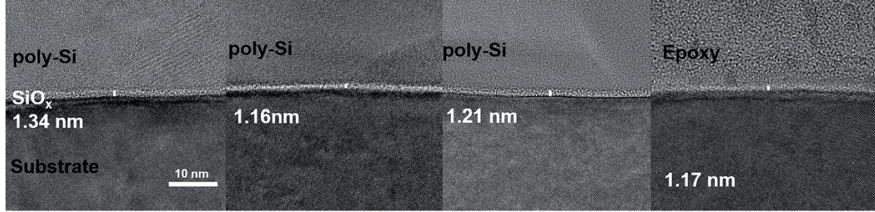

Fig. 5 (a) $i V_{O C}$ as a function of poly-Si etching thickness and TEM images of $\mathrm{POCl}_{3}$ diffused poly-Si contacts (b) before annealing, (c) after annealing at $950{ }^{\circ} \mathrm{C}$ for $30 \mathrm{~min}$, and after the etching of poly-Si measuring (d) $150 \mathrm{~nm}$ and (e) $300 \mathrm{~nm}$. (f, g, h, i) more magnified images of $(b, c, d, e)$, respectively.

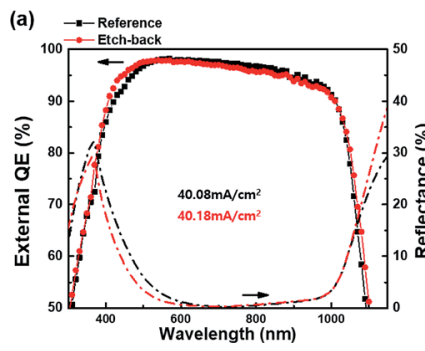

(b) $\rightarrow$ Reference

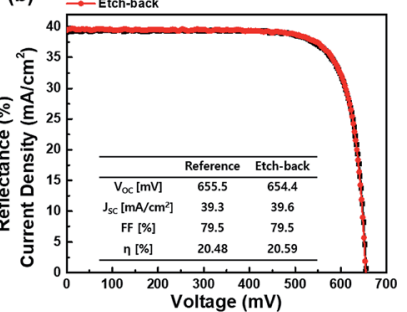

Fig. 6 (a) EQE and reflectance graph, and (b) IV curve.

shown in Fig. 6(a). Moreover, for the cell, $J_{\mathrm{SC}}$ increased from 39.3 to $39.6 \mathrm{~mA} \mathrm{~cm}^{-2}$ and the efficiency increased from $20.48 \%$ to $20.59 \%$ by etching poly-Si from 300 to $50 \mathrm{~nm}$, with a constant fill factor and slightly decreased $V_{\text {OC }}$. Finally, we confirmed that the etching of poly-Si does not affect $V_{\mathrm{OC}}$ and the passivation quality but further enhances $J_{\mathrm{SC}}$ by reducing the loss caused by light absorption.

\section{Summary}

In this study, the roles of poly-Si were elucidated by varying the annealing temperature and time, as well as the thickness and doping concentration of poly-Si. The results indicated that polySi played the role of (1) contact, as the different doping concentrations of poly-Si can change the work function and cause different selectivity, (2) barrier layer for metallization and in-diffusion, as poly-Si is needed between $\mathrm{SiO}_{x}$ and metal to avoid the destruction of $\mathrm{SiO}_{x}$ layer and maintain the passivation quality, and (3) gettering, which improves the bulk quality. Moreover, by analyzing the hydrogenation concentration after hydrogenation, we confirmed that hydrogen passivation at $\mathrm{SiO}_{x}$ is important to achieve high $\mathrm{i} V_{\text {OC }}$. To further improve the cell efficiency, we etched a poly-Si layer and found that the measured $\mathrm{i} V_{\text {OC }}$ was not affected after the etching of this layer. By compiling all results, we concluded that the efficiency of the passivating contact silicon solar cell was improved by etching poly-Si via facilitation of high-quality passivation and low IR carrier absorption. Finally, the solar cell exhibited increased efficiency from $20.48 \%$ to $20.59 \%$ owing to the increased $J_{\mathrm{SC}}$ from 39.3 to $39.6 \mathrm{~mA} \mathrm{~cm}{ }^{-2}$ with a constant $V_{\mathrm{OC}}$ and fill factor.

\section{Conflicts of interest}

There are no conflicts to declare.

\section{Acknowledgements}

This research was supported by the New \& Renewable Energy Core Technology Program of the Korea Institute of Energy Technology Evaluation and Planning (KETEP), a financial grant from the Ministry of Trade, Industry \& Energy, Republic of Korea (No. 20163030014020), and the Technology Development Program to Solve Climate Changes of the National Research Foundation (NRF) funded by the Ministry of Science and ICT (NRF-2017M1A2A2087351). This work was supported by the "Human Resources Program in Energy Technology" of the Korea Institute of Energy Technology Evaluation and Planning (KETEP), with financial support from the Ministry of Trade, Industry and Energy, Republic of Korea (No. 20154030200760).

\section{References}

1 A. Richter, M. Hermle and S. W. Glunz, IEEE J. Photovolt., 2013, 3, 1184-1191.

2 U. Würfel, A. Cuevas and P. Würfel, IEEE J. Photovolt., 2014, 5, 1-9.

3 S. W. Glunz and F. Feldmann, Sol. Energy Mater. Sol. Cells, 2018, 185, 260-269.

4 X. You-Peng, G. Chao, W. Tao and Z. Lang, Acta Phys. Sin., 2017, 66, 158801.

5 C. Battaglia, A. Cuevas and S. De Wolf, Energy Environ. Sci., 2016, 9, 1552-1576.

6 J. Melskens, B. W. H. van de Loo, B. Macco, L. E. Black, S. Smit and W. M. M. Kessels, IEEE J. Photovolt., 2018, 8, 373-388.

7 F. Feldmann, G. Nogay, J. Polzin, B. Steinhauser, A. Richter, A. Fell, C. Schmiga, M. Hermle and S. W. Glunz, IEEE J. Photovolt., 2018, 8, 1503-1509.

8 F. Feldmann, M. Bivour, C. Reichel, M. Hermle and S. W. Glunz, 28th European PV solar energy conference and exhibition, 2013.

9 U. Römer, R. Peibst, T. Ohrdes, B. Lim, J. Krügener, E. Bugiel, T. Wietler and R. Brendel, Sol. Energy Mater. Sol. Cells, 2014, 131, 85-91. 
10 A. Liu, D. Yan, S. P. Phang, A. Cuevas and D. Macdonald, Sol. Energy Mater. Sol. Cells, 2018, 179, 136-141.

11 A. Liu, D. Yan, J. Wong-Leung, L. Li, S. P. Phang, A. Cuevas and D. Macdonald, ACS Appl. Energy Mater., 2018, 1, 22752282.

12 D. Yan, A. Cuevas, J. Bullock, Y. Wan and C. Samundsett, Sol. Energy Mater. Sol. Cells, 2015, 142, 75-82.

13 B. Nemeth, D. L. Young, M. R. Page, V. LaSalvia, S. Johnston, R. Reedy and P. Stradins, J. Mater. Res., 2016, 31, 671-681.

14 F. Feldmann, M. Bivour, C. Reichel, H. Steinkemper, M. Hermle and S. W. Glunz, Sol. Energy Mater. Sol. Cells, 2014, 131, 46-50.

15 K. Masuko, M. Shigematsu, T. Hashiguchi, D. Fujishima, M. Kai, N. Yoshimura, T. Yamaguchi, Y. Ichihashi, T. Mishima, N. Matsubara, et al., IEEE J. Photovolt., 2014, 4, 1433-1435.

16 K. Yoshikawa, H. Kawasaki, W. Yoshida, T. Irie, K. Konishi, K. Nakano, T. Uto, D. Adachi, M. Kanematsu, H. Uzu and K. Yamamoto, Nat. Energy, 2017, 2, 17032.

17 M. A. Green, Y. Hishikawa, E. D. Dunlop, D. H. Levi, J. HohlEbinger, M. Yoshita and A. W. Ho-Baillie, Prog. Photovoltaics Res. Appl., 2019, 27, 3-12.

18 M. Taguchi, A. Yano, S. Tohoda, K. Matsuyama, Y. Nakamura, T. Nishiwaki, K. Fujita and E. Maruyama, IEEE J. Photovolt., 2014, 4, 96-99.

19 K. Masuko, M. Shigematsu, T. Hashiguchi, D. Fujishima, M. Kai, N. Yoshimura, T. Yamaguchi, Y. Ichihashi, T. Mishima, N. Matsubara, et al., IEEE J. Photovolt., 2014, 4, 1433-1435.

20 A. Richter, J. Benick, F. Feldmann, A. Fell, M. Hermle and S. W. Glunz, Sol. Energy Mater. Sol. Cells, 2017, 173, 96-105. 21 E. Yablonovitch, T. Gmitter, R. Swanson and Y. Kwark, Appl. Phys. Lett., 1985, 47, 1211-1213.

22 A. Rohatgi, B. Rounsaville, Y.-W. Ok, A. M. Tam, F. Zimbardi, A. D. Upadhyaya, Y. Tao, K. Madani, A. Richter, J. Benick, et al., IEEE J. Photovolt., 2017, 7, 1236-1243.

23 P. Brüesch, T. Stockmeier, F. Stucki and P. Buffat, J. Appl. Phys., 1993, 73, 7677-7689.

24 L. Elstner, E. Conrad, H. Eschrich, W. Füssel and H. Flietner, Phys. Status Solidi B, 1996, 194, 79-90.

25 F. Haase, C. Hollemann, S. Schäfer, A. Merkle, M. Rienäcker, J. Krügener, R. Brendel and R. Peibst, Sol. Energy Mater. Sol. Cells, 2018, 186, 184-193.

26 T. Wietler, D. Tetzlaff, J. Krügener, M. Rienäcker, F. Haase, Y. Larionova, R. Brendel and R. Peibst, Appl. Phys. Lett., 2017, 110, 253902.

27 G. Yang, A. Ingenito, O. Isabella and M. Zeman, Sol. Energy Mater. Sol. Cells, 2016, 158, 84-90.
28 G. Yang, A. Ingenito, N. van Hameren, O. Isabella and M. Zeman, Appl. Phys. Lett., 2016, 108, 033903.

29 M. K. Stodolny, J. Anker, B. L. Geerligs, G. J. Janssen, B. W. van de Loo, J. Melskens, R. Santbergen, O. Isabella, J. Schmitz, M. Lenes, et al., Energy Procedia, 2017, 124, 635-642.

30 H. Park, H. Park, S. J. Park, S. Bae, H. Kim, J. W. Yang, J. Y. Hyun, C. H. Lee, S. H. Shin, Y. Kang, et al., Sol. Energy Mater. Sol. Cells, 2019, 189, 21-26.

31 G. Nogay, J. Stuckelberger, P. Wyss, Q. Jeangros, C. Allebé, X. Niquille, F. Debrot, M. Despeisse, F.-J. Haug, P. Löper and C. Ballif, ACS Appl. Mater. Interfaces, 2016, 8, 3566035667.

32 A. Ulyashin, R. Job, M. Scherff, M. Gao, W. Fahrner, D. Lyebyedyev, N. Roos and H.-C. Scheer, Thin Solid Films, 2002, 403-404, 359-362.

33 K. v. Maydell, E. Conrad and M. Schmidt, Prog. Photovoltaics Res. Appl., 2006, 14, 289-295.

34 T. Wang, E. Iwaniczko, M. Page, D. Levi, Y. Yan, H. Branz and Q. Wang, Thin Solid Films, 2006, 501, 284-287.

35 M. Jeon, S. Yoshiba and K. Kamisako, Curr. Appl Phys., 2010, 10, S237-S240.

36 Y. Lee, S. Han, S. Kim, S. Md Iftiquar, Y.-J. Lee, J. Yoo, A. Dao and J. Yi, J. Photonics Energy, 2014, 4, 043094.

37 A. Richter, J. Benick, F. Feldmann, A. Fell, M. Hermle and S. W. Glunz, Sol. Energy Mater. Sol. Cells, 2017, 173, 96-105.

38 S. Choi, K. Hong Min, M. Sang Jeong, J. In Lee, M. G. Kang, H.-E. Song, Y. Kang, H.-S. Lee, D. Kim and K.-H. Kim, Sci. Rep., 2017, 7, 12853.

39 H. T. Nguyen, A. Liu, D. Yan, H. Guthrey, T. N. Truong, M. Tebyetekerwa, Z. Li, Z. Li, M. M. Al-Jassim, A. Cuevas and D. Macdonald, ACS Appl. Energy Mater., 2018, 1, 66196625.

40 A. Moldovan, F. Feldmann, M. Zimmer, J. Rentsch, J. Benick and M. Hermle, Sol. Energy Mater. Sol. Cells, 2015, 142, 123127.

41 H. Steinkemper, F. Feldmann, M. Bivour and M. Hermle, IEEE J. Photovolt., 2015, 5, 1348-1356.

42 R. A. Sinton and A. Cuevas, Appl. Phys. Lett., 1996, 69, 25102512.

43 H. Kim, S. Bae, K.-s. Ji, S. M. Kim, J. W. Yang, C. H. Lee, K. D. Lee, S. Kim, Y. Kang, H.-S. Lee, et al., Appl. Surf. Sci., 2017, 409, 140-148.

44 H. Wagner, A. Dastgheib-Shirazi, B. Min, A. E. Morishige, M. Steyer, G. Hahn, C. del Cañizo, T. Buonassisi and P. P. Altermatt, J. Appl. Phys., 2016, 119, 185704.

45 R. Tsu and L. Esaki, Appl. Phys. Lett., 1973, 22, 562-564. 